\title{
IMPLEMENTASI AUGMENTED REALITY SEBAGAI MEDIA PROMOSI INTERAKTIF UNTUK KATALOG FOOD AND BEVERAGE PADA HOKCAFE
}

\author{
Rima Rizqi Wijayanti \\ Program Studi Informatika \\ Fakultas Teknik Universitas Muhammadiyah Tangerang \\ Jl. Perintis Kemerdekaan 1/33 Cikokol Kota Tangerang \\ Email:rima.rizqi@umt.ac.id
}

\begin{abstract}
The business of Food And Beverages is a business that is currently showing rapid development, but the media still used uniform promotion by using the brochure display only $2 D$ objects and lack of differentiation in doing promotion, therefore researchers initiative to design and make the application of augmented reality that can make it easier buyers and increased power consumption tastes to see visual form menu and as an interactive media promotions using the technology of augmented reality based android tailored to needs.The making of the application is created using the Unity $3 D$ software with programming languages C \#, Blender $3 D$ for $3 D$ object formation, where each stage of the system is done in a sequence repeated quickly. The results obtained from this research that is has made application augmented reality on a catalog of Food And Beverages based on android
\end{abstract}

Keywords: Augmented Reality, Food And Beverages, Unity3D, Blender3D

\section{PENDAHULUAN}

Saat ini kemajuan di bidang teknologi informasi mampu memberikan inovasi baru dalam dunia periklanan. Berawal dari bentuk sederhana berupa pemasangan banner digital pada website, hingga yang terbaru penerapan konsep teknologi Augmented Reality. Teknologi yang menggabungkan benda maya dua dimensi maupun tiga dimensi ke dalam sebuah lingkungan nyata ini. Apabila digunakan dalam iklan, maka mampu memberikan feel, dan experience tersendiri bagi calon konsumen suatu produk atau layanan. calon konsumen suatu produk seakan-akan diajak untuk merasakan pengalaman saat menggunakan produk. Sehingga beriklan dapat dilakukan dengan lebih interaktif dan mampu menciptakan hubungan yang erat antara konsumen dengan produk
Menurut Rahardja (Arief B., 2015: 1), teknologi AR diyakini akan mengubah dinamika marketing dengan tools yang semakin canggih dan nyata, dengan penerapan yang sangat luas di berbagai lini bisnis dan industri. Teknologi AR bagi dunia periklanan saat ini sedang berkembang pesat di seluruh dunia. Sebut saja aplikasi Augmented Reality Automotive, Augmented Reality Furniture, Augmented Reality Education, Augmented Reality Print Materials, dan masih banyak lagi. Teknologi Augmented Reality. dapat menjadi alat yang hebat untuk menunjukkan kepada konsumen potensial dari produk yang diiklankan.

Hokcafe merupakan salah satu tempat usaha yang sedang berkembang dan sudah mempunyai toko baru untuk tempat menjual produknya, untuk itu Hokcafe membutuhkan media promosi penjualan yang dapat digunakan 
untuk proses penjualan produknya, media promosi yang diharapkan adalah sebuah media dengan bentuk baru yang masih jarang digunakan diberbagai kalangan media. Salah satu gagasan untuk media promosi ini adalah teknologi Augmented Reality, yaitu medai promosi berbentuk digital imaging sebagai bentuk virtual yang dapat dilihat secara langsung oleh pelanggan.

Berdasarkan uraian diatas maka diperlukan suatu aplikasi sebagai media promosi interaktif, dalam bentuk 3D yang diharapkan dapat memberikan informasi pada Counter Food And Beverages agar dapat membantu penjualan serta promosi dengan efektif.

\section{TINJAUAN PUSTAKA}

\section{A. Augmented Reality}

Augmented Reality (AR) atau dalam bahasa Indonesia disebut realitas tertambah adalah teknologi yang menggabungkan benda maya dua dimensi dan tiga dimensi ke dalam sebuah lingkungan nyata lalu memproyeksikan benda-benda maya tersebut dalam waktu nyata. Benda-benda maya berfungsi menampilkan informasi yang tidak dapat diterima oleh manusia secara langsung. Hal ini membuat realitas tertambah berguna sebagai alat untuk membantu persepsi dan interaksi penggunanya dengan dunia nyata. Ada banyak definisi dari augmented reality tetapi asumsi umum adalah bahwa augmented reality memungkinkan perspektif yang diperkaya dengan melapiskan objek virtual pada dunia nyata dengan cara yang mengajak penonton bahwa objek virtual adalah bagian dari lingkungan nyata. Oleh karena itu. Menurut Milgran dan Furnio (1994: 1), "Augmented Reality is continuum that spans an entirely real environment to a parely virtual environment. In between are Augmented Reality (closer to the real environment). And Virtual Reality (closer to the virtual environment)". Sebuah kontinum yang mencakup lingkungan yang sama sekali nyata untuk lingkungan virtual murni. Diantaranya adalah augmented reality (mendekati lingkungan nyata) dan virtual augmented (mendekati lingkungan virtual).

\section{Blender 3D}

Blender3D adalah perangkat lunak Open Source grafika komputer 3D. Perangkat lunak ini digunakan untuk membuat film animasi, efek visual, model cetak 3D, aplikasi 3D interaktif dan permainan video. Blender memiliki beberapa fitur termasuk pemodelan $3 \mathrm{D}$, penteksturan, penyunting gambar bitmap, penulangan, simulasi cairan dan asap, simulasi partikel, animasi, penyunting video, pemahat digital, dan rendering. Kemampuan untuk membuat game juga dimiliki oleh Blender3D, ini juga merupakan salah satu keunggulan Blender3D yang sangat unik. Blender dapat memprogram game dengan menggunakan script bahasa pemrograman Phyton. Blender menyediakan interface yang professional untuk memprogram sebuah game. Blender juga mengetahui kebutuhan para programmer game 3D untuk menciptakan game secara cepat. Untuk itu, Blender menyediakan fasilitas Game Logic, yaitu beragam tools siap pakai (https://www.blender.org/about/).

\section{B. Unity 3D}

Unity3D adalah sebuah game engine yang berbasis cross-platform. Unity dapat digunakan untuk membuat sebuah game yang bisa digunakan pada perangkat komputer, ponsel pintar android, iPhone, PS3, hingga konsol XBOX. Unity3D adalah sebuah sebuah tool yang terintegrasi untuk membuat game, arsitektur bangunan dan simulasi. Unity3D dapat digunakan untuk games PC dan games Online. Untuk games Online diperlukan sebuah plugin, yaitu Unity Web Player, yang mana fungsi tersebut seperti Flash Player pada Browser. Unity3D tidak dirancang untuk proses desain atau modelling, dikarenakan unity bukan tool untuk mendesain. Jika user ingin mendesain, pergunakan 3D editor lain seperti 3dsmax atau Blender3D. Banyak hal yang bisa dilakukan dengan unity, ada fitur audio reverb zone, particle effect, dan Sky Box untuk menambahkan langit. Fitur scripting yang disediakan, mendukung 3 bahasa pemrograman, 
JavaScript, C\#, dan Boo. Flexible and EasyMoving, rotating, dan scaling objects hanya perlu sebaris kode. Begitu juga dengan Duplicating, removing, dan changing properties. Visual Properties Variables yang di definisikan dengan scripts ditampilkan pada Editor. Bisa digeser, di drag and drop, bisa memilih warna dengan color picker. Berbasis .NET. Artinya penjalanan program dilakukan dengan Open Source .NET platform, Mono (https://unity3d.com/).

\section{Food \& Beverage}

Menurut Rachman Arief , Abd (2005:113) menyebutkan bahwa food and beverage department yaitu bagian yang bertugas mengolah, memproduksi dan menyajikan makanan dan minuman untuk keperluan tamu hotel, baik dalam kamar, restoran/ coffee shop, banquet (resepsi pertemuan), makanan karyawan, dan sebagainya.

Bagian ini dipimpin oleh seorang Food and Beverage Director/ F \& B Manager yang dibantu oleh seorang Asst. F \& B Manager, seorang sekretaris F \& B Manager, dan beberapa Department Head seperti : Exc. Chef / Chef De'Cuisiene, Restoran Manager, Bar Manager, Banquet Manager, Chief Stewarding, dan beberapa Section Head dilingkungan F \& B Department.

\section{METODOLOGI PENELITIAN}

\section{A. Metode Research \& Development $(\mathrm{R} \& \mathrm{D})$}

Menurut Sukmadinata (2011), produk tersebut tidak selalu berbentuk benda atau perangkat keras seperti buku, modul alat bantu pembelajaran, tetapi dapat juga berupa perangkat lunak atau program/aplikasi komputer, model pendidikan, pembelajaran, atau pelatihan.

Borg \& Gall (1989) mendefinisikan hal ini dengan kalimat, "Educational research and development $(\mathrm{R} \& \mathrm{D})$ is a process used to develop and validate educational products".
Sedangkan menurut Sugiyono (2009), metode penelitian dan pengembangan adalah metode penelitian yang digunakan untuk menghasilkan produk tertentu, dan menguji keefiktifan produk tersebut.

Menurut (Pratama, 2012) Metode Research and Development yang diungkapkan Borg dan Gall (1989) terbagi atas beberapa tahapan, diantaranya :

1. Penelitian dan pengumpulan data (research and information collecting).

2. Perencanaan (planning).

3. Pengembangan draft produk (develop preliminary form of product).

4. Uji coba lapangan awal (preliminary field testing).

5. Merevisi hasil uji coba (main product revision).

6. Uji coba lapangan (main field testing).

7. Penyempurnaan produk hasil uji lapangan (operasional product revision).

8. Uji pelaksanaan lapangan (operasional field testing).

9. Penyempurnaan akhir produk (final product revision).

10. Diseminasi dan implementasi (dissemination and implementation).

Dalam penelitian ini, proses rekayasa perangkat lunak sangat dominan sehingga perlu adanya penyelarasan. Hal ini agar melalui tahapan analisis persyaratan, desain, coding, dan testing. Sehingga dapat dihasilkan tahapan penelitian yang sesuai dengan rumusan dan tujuan penelitian yang dapat disimpulkan sebagai berikut (Haryati, 2012):

1. Tahap Analisis

2. Tahap Desain

3. Tahap Pengembangan

4. Tahap Pengujian

5. Pembuatan Laporan

Penulis dalam merancang aplikasi Augmented Reality Sebagai Media Promosi Interaktif Untuk Katalog Food And Beverage Pada Hokcafe menggunakan metode R \& D. Penulis menerjemahkan langkah demi langkah yang ada dalam proses $R \& D$ sebagai berikut: 


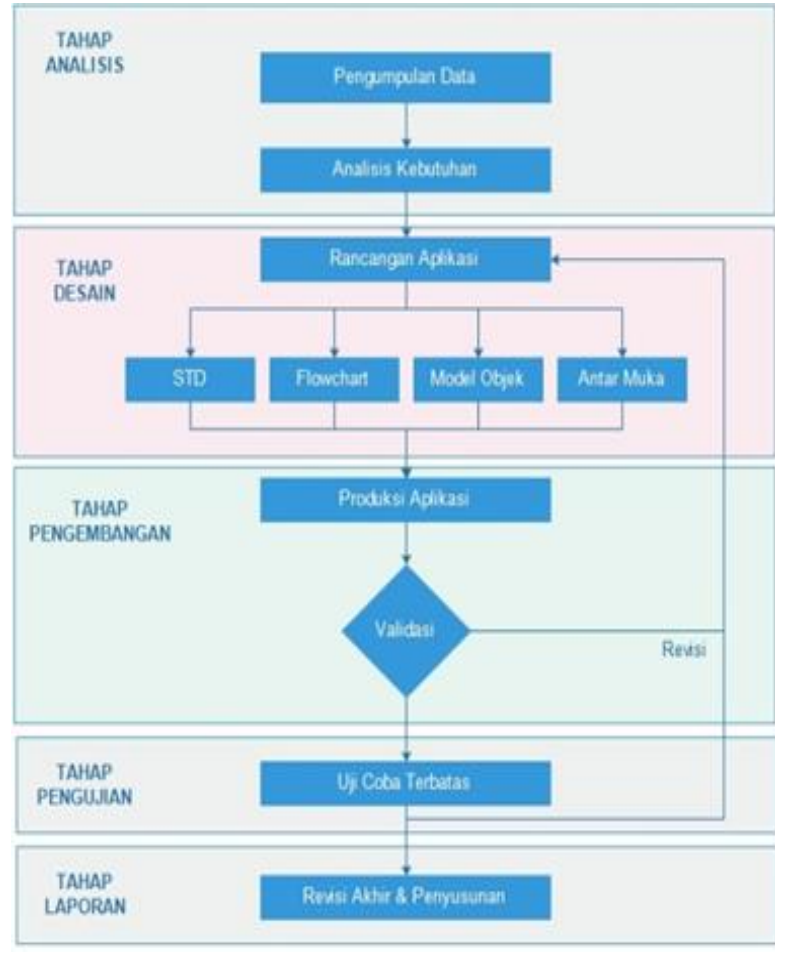

Gambar 1. Diagram R\&D Penelitian

Penjelasan alur diagram metode R\&D:

1. Tahap Analisis

Tahap analisis meliputi analisa kebutuhan dan pengumpulan data. Pengumpulan data dilakukan dengan cara observasi dan wawancara secara langsung di lokasi penelitian yaitu Hokcafe.

2. Tahap Desain

Perancangan yang dilakukan adalah pembuatan State Transition Diagram (STD), perancangan proses, perancangan tampilan antar muka, dan perancangan model objek.

3. Tahap Pengembangan

Tahap pengembangan merupakan tahap dimana hasil rancangan dari tahap sebelumnya (STD, Flowchart Proses, Tampilan, Model Objek) dan diimplementasikan ke pembuatan aplikasi menggunakan Unity 3D. Proses pengembangan ini bertujuan untuk menghasilkan produk awal, dan selanjutnya dilakukan pengujian dengan metode black box testing.

4. Tahap Pengujian

Pengujian dilakukan dengan metode black box testing. Pengujian ini dilakukan untuk memastikan apakah hasil aplikasi sudah sesuai dengan tujuan yang diharapkan sebelumnya.

5. Tahap Laporan

Tahap akhir adalah penulisan laporan yang disusun sesuai dengan ketentuan yang tercantum.

\section{HASIL DAN PEMBAHASAN}

A. Analisa Sistem

Analisis sistem ini digunakan untuk proses penguraian dari suatu sistem yang utuh ke dalam bagian-bagian komponennya dengan maksud untuk mengidentifikasi dan mengevaluasi permasalahan, kesempatan, hambatan yang terjadi dan kebutuhan yang diharapkan sehingga dapat diusulkan solusi atau perbaikan. Dari hasil analisis tersebut dapat dirancang atau diperbaiki menjadi sebuah sistem yang lebih efektif dan efisien. Sistem yang dibuat merupakan aplikasi untuk mendeteksi marker dan menampilkan objek tiga dimensi yang telah dibuat dengan menggunakan software tiga dimensi (3DBlender). Objek yang dibuat merupakan Pastry, seolah-olah pengguna berinteraksi langsung dengan objek virtual dalam dunia nyata yang disajikan dalam bentuk katalog.

\section{B. Analisa Sistem yang berjalan}

Prosedur yang sedang berjalan saat ini adalah sebagai berikut : 


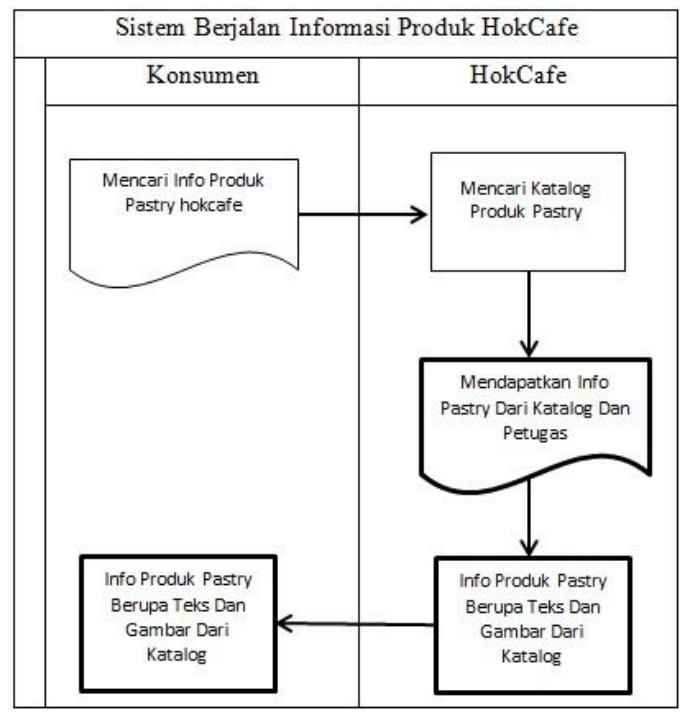

Gambar 2. Flowmap Sistem Berjalan

Keterangan Gambar:

1. Konsumen adalah para calon pembeli di hokcafe.

2. Cara untuk mengetahui informasi yang akan didapat, yaitu :

Katalog Brosur, Media ini cukup mudah untuk mengetahui informasi tentang Pastry yang tersedia, penyampaian informasi pada katalog ini berupa gambar 2D dan teks.

Dari gambaran prosedur media yang didapat untuk mengakses berbagai informasi pada katalog, teknologi augmented reality dapat dijadikan sebagai media alternatif sehingga penyampaian informasi tentang Pastry yang akan dijual menjadi lebih menarik dan interaktif.

\section{Analisa Masalah}

Analisa masalah adalah langkah awal dari analisis sistem yang diperlukan untuk mengetahui pemasalahan apa saja yang terjadi didalam sistem yang telah berjalan. Berdasarkan analisis sistem yang dilakukan dengan cara mengamati pemasaran yang telah dilakukan selama ini adalah pihak pemasaran hanya memberikan informasi dan gambaran tentang pastry yang akan dijual kepada para calon pembeli dalam bentuk foto satu arah yang terdapat pada katalog.

\section{Analisis Arsitektur Sistem}

Pada arsitektur aplikasi yang akan dibangun terdiri dari beberapa komponen, yaitu : User adalah pengguna yang menggunakan aplikasi katalog berbasis augmented reality, User mengarahkan marker sehingga marker dapat tertangkap olah kamera. Kemudian dari gambar yang didapat dari kamera sistem komputer melakukan tracking marker untuk mengidentifikasi marker yang digunakan oleh pengguna. Perangkat melakukan render objek 3D yang digunakan dalam aplikasi. User dapat melihat hasil manipulasi system melalui layar perangkat.

Gambaran arsitektur sistem dapat dilihat pada gambar 2

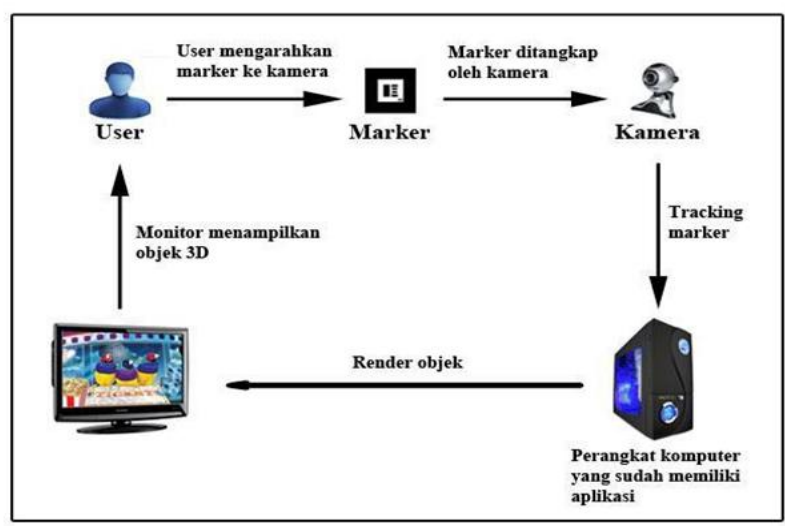

Gambar 3. Arsitektur Sistem

E. Analisa Sistem Usulan

Melihat masih dipakainya cara manual dalam proses pemesanan selama ini, tentunya kurang menarik dalam pelaksanaannya. Di sisi lain belum banyak perusahaan yang mengunakan sistem ini dalam segalaaktivitasnya, terlebih lagi dalam hal penjualan. Oleh karena itu penulis mengusulkan adanya komputerisasi sistem dalam pengelolaan pemesanan pada Hokcafe. Dengan adanya komputerisasi sistem diharapkan dapat mengatasi permasalahan-permasalahan yang ada dan menyempurnakan sistem manual yang sudah ada. 
1. Usecase Diagram

Mendiskripsikan fungsi dari sebuah sistem dari perspektif pengguna, use case diagram bekerja dengan cara mendeskripsikan tipikal interaksi antara pengguna sebuah sistem dengan sistemnya sendiri. Didalam sistem terdapat pengguna yaitu pemakai aplikasi, peran aktor yang ada dapt dilihat pada diagram Use Case pada gambar berikut.

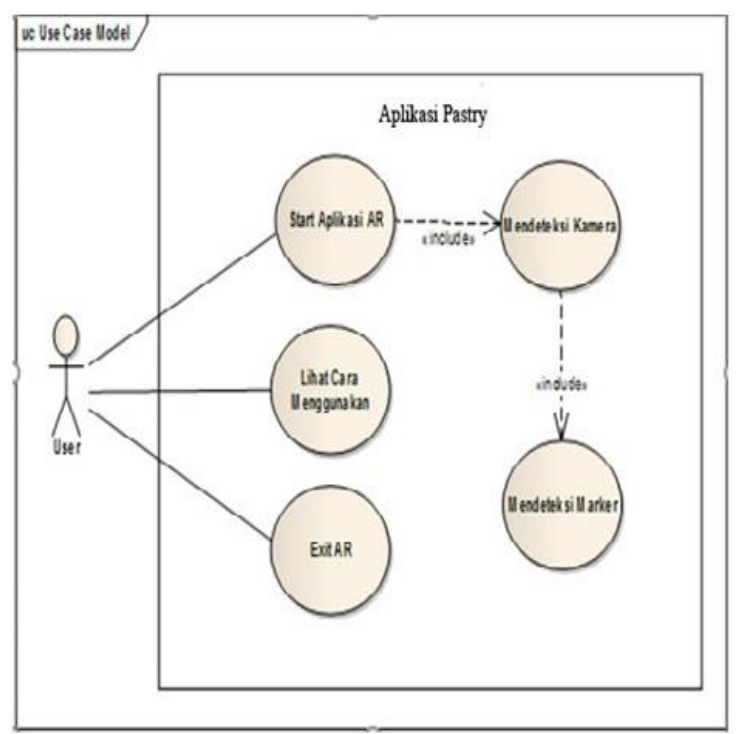

Gambar 7. Usecase Diagram Hokcafe

Keterangan Use Case Diagram :

a. User memilih menu Start AR, terdapat deteksi kamera dan marker oleh sistem.

b. User memilih Lihat Cara Menggunakan.

c. User memilih menu Exit AR.

2. Activity Diagram

Activity diagram memodelkan eventevent yang terjadi pada Use Case dan digunakan untuk pemodelan aspek dinamis dari sistem. a. Activity Diagram Start

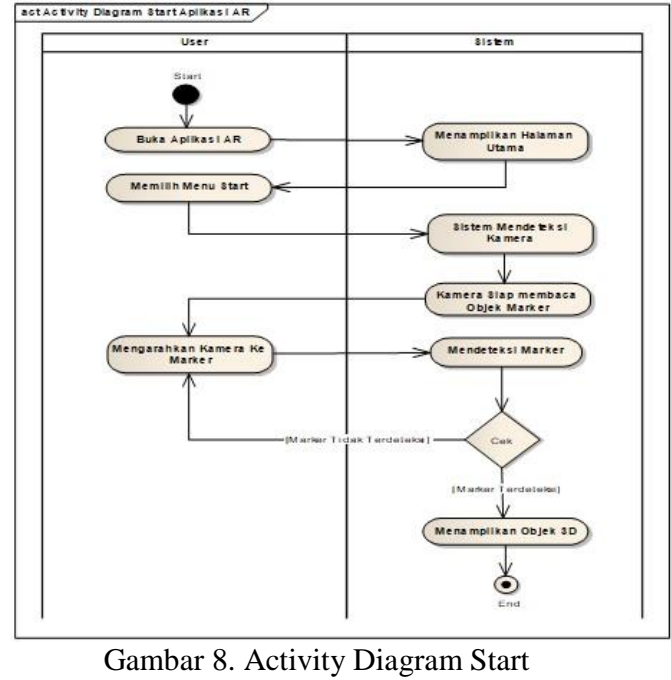

Keterangan Diagram :

1) User membuka aplikasi dan sistem menampilkan menu utama.

2) User memilih menu Start AR, sistem akan mendeteksi kamera lalu kamera yang sudah siap akan dapat membaca objek marker.

3) User mengarahkan kamera ke marker, sistem mendeteksi marker, jika terdeteksi maka sistem akan menampilkan objek 3D dan jika tidak terdeteksi maka user akan mengulangi mengarahkan kamera ke marker sampai terdeteksi dengan baik oleh kamera. 


\section{b. Activity Diagram Tutorial}

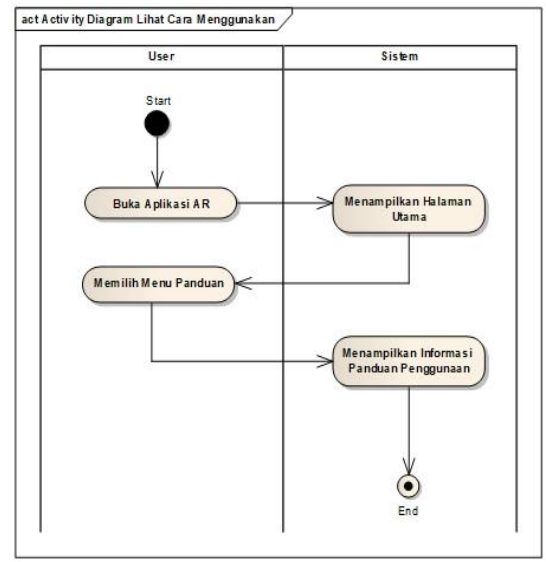

Gambar 9. Activity Diagram Tutorial

Keterangan Diagram :

1) User membuka aplikasi $A R$.

2) Sistem merespon dengan memberikan tampilan menu utama.

3) User kemudian memilih menu panduan AR yang kemudian sistem akan menampilkan informasi dari menu yang telah dipilih.

\section{c. Activity Diagram Exit}

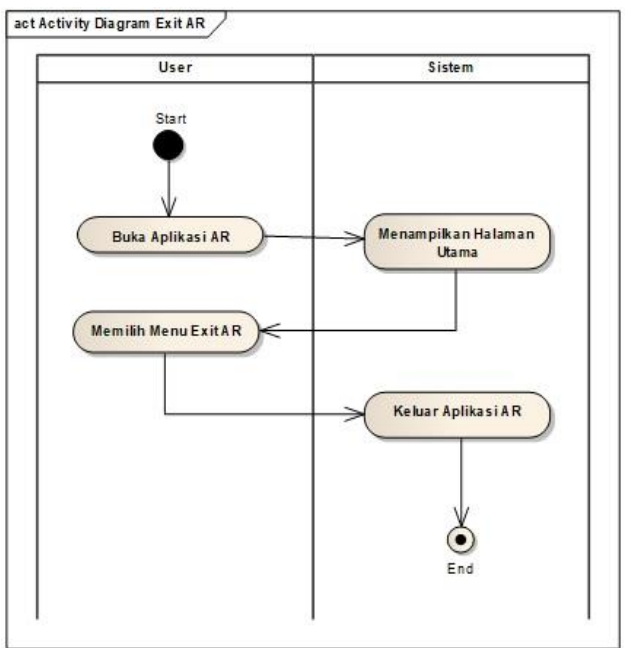

Gambar 10. Activity Diagram Exit

Keterangan Diagram :

1) User membuka aplikasi AR.

2) Sistem menampilkan halaman utama.
3) User memilih menu Exit, dan sistem akan memberi respon dengan keluar dari aplikasi.

3. Sequance Diagram

a. Sequance Diagram Start

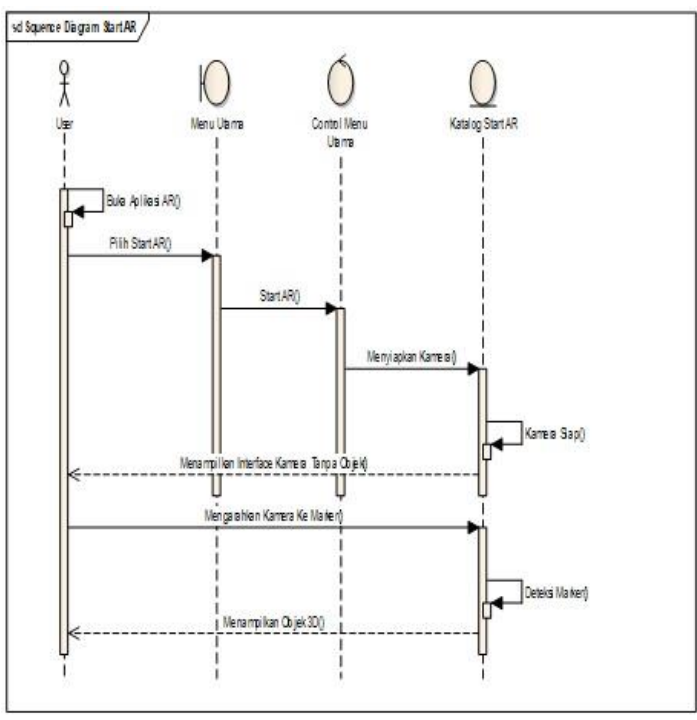

Gambar 11. Sequance Diagram Start

Keterangan Diagram :

1) User membuka aplikasi dan sistem menampilkan menu utama.

2) User memilih menu Start AR, sistem akan mendeteksi kamera lalu kamera yang sudah siap akan dapat membaca objek marker.

3) User mengarahkan kamera ke marker, sistem mendeteksi marker, jika terdeteksi maka sistem akan menampilkan objek 3D dan jika tidak terdeteksi maka user akan mengulangi mengarahkan kamera ke marker sampai terdeteksi dengan baik oleh kamera. 
b. Sequance Diagram Tutorial

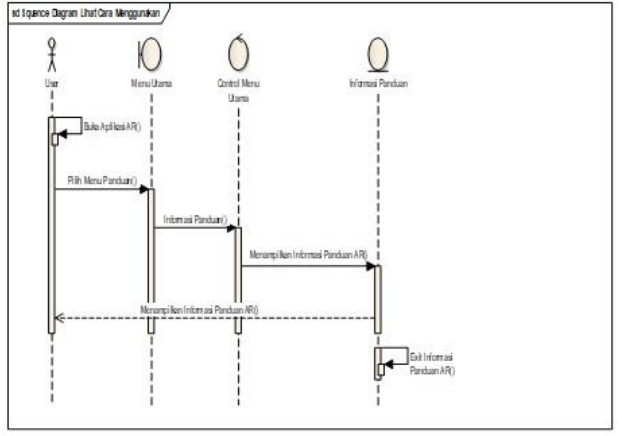

Gambar 12. Sequance Diagram Tutorial

Keterangan Diagram :

1) User membuka aplikasi AR.

2) Sistem merespon dengan memberikan tampilan menu utama.

User kemudian memilih menu panduan AR yang kemudian sistem akan menampilkan informasi dari menu yang telah dipilih.

\section{c. Sequance Diagram Exit}

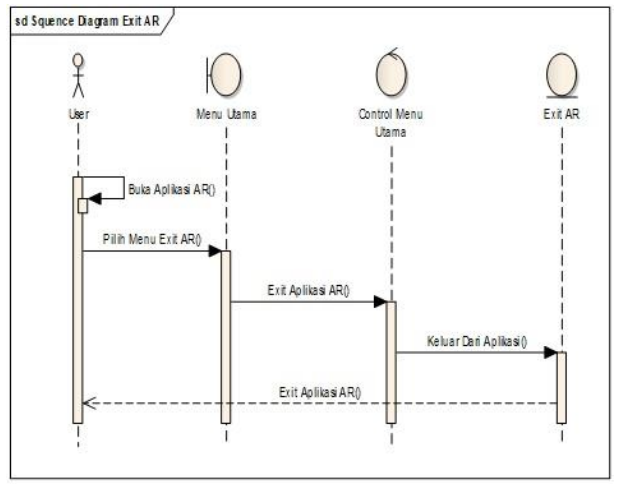

Gambar 13. Sequance Diagram Exit

Keterangan Diagram :

1) User membuka aplikasi AR.

2) Sistem merespon dengan memberikan tampilan menu utama.

3) User kemudian memilih menu panduan AR yang kemudian sistem akan menampilkan informasi dari menu yang telah dipilih.

\section{Class Diagram}

Class Diagram adalah diagram UML (Unified Modelling Language) yang menggambarkan kelas-kelas yang berhubungan dengan sistem antara satu dengan yang lain yang berisi atribut dan operasi. Untuk lebih jelasnya dapat dilihat Gambar 14

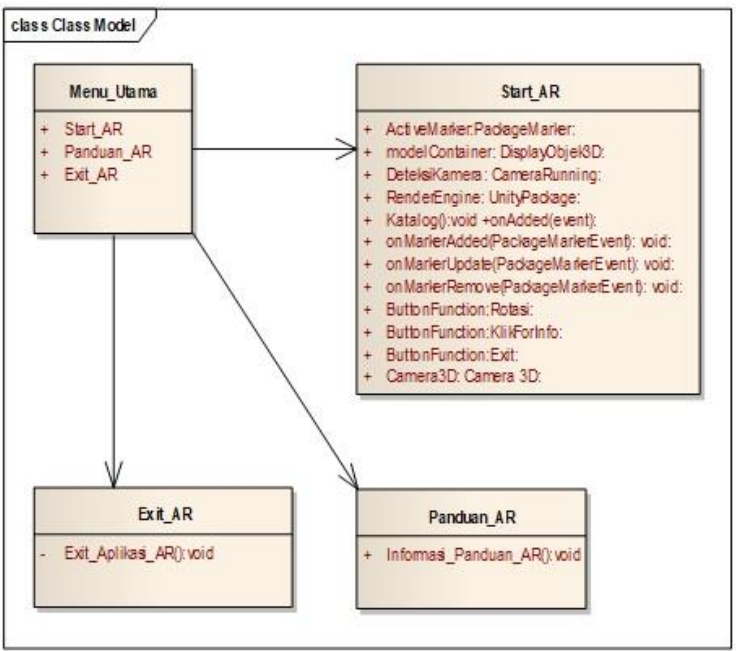

Gambar 14. Class Diagram

\section{Perancangan Marker}

Marker adalah sebuah pola yang berbentuk gambar yang mana akan dikenali oleh kamera yang bersifat real time. Untuk membuat marker, ada beberapa langkah yang harus dilakukan, diantaranya adalah sebagai berikut :

a. Pembuatan Marker pada aplikasi Unity melalui web http://developer.vuforia.com

b. kemudian login dan pilih tab Develop.

c. Pada Tab License Manager, buat license manager yang nantinya license tersebut di copy dan digunakan pada unity sebagai rendering kamera untuk membaca objek.

d. Pilih Tab Target Manager, Add Database yang nantinya menjadi package marker diharuskan untuk upload gambar yang sudah di desain, gambar tersebut akan manjadi marker yang digunakan sebagai package marker pada unity3D.

e. Pilih database yang sudah dibuat, kemudian download database tersebut. Package marker tersebut ber-ekstensi "unitypackage".

Setiap patern marker mewakili 1 objek sebagai identitas objek dan 1 titik sebagai penanda marker tersebut. Berikut marker yang digunakan pada pembangunan aplikasi,yaitu 


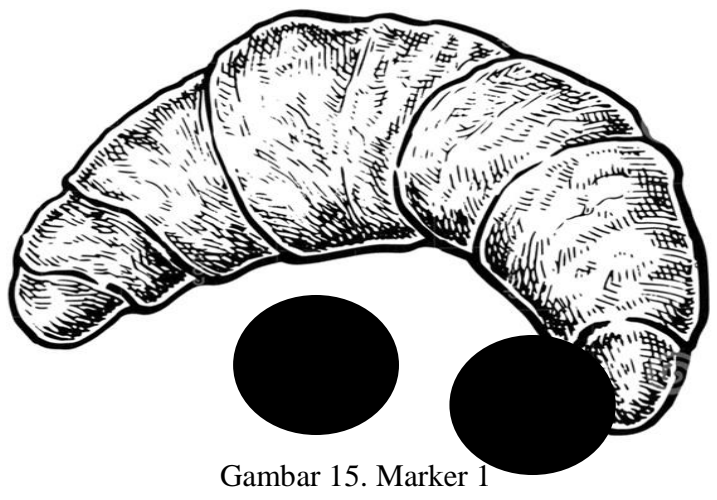

Marker 1 digunakan sebagai identitas objek dari croissant, Objek croissant akan muncul ketika kamera mendeteksi marker 1.

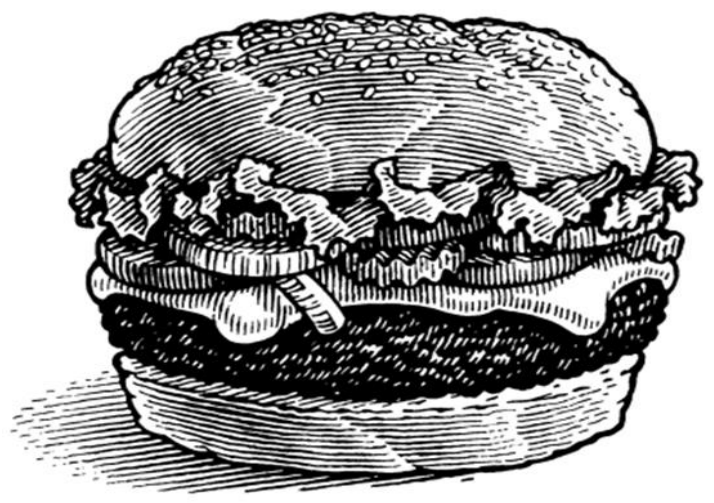

Gambar 16. Marker 2

Marker 2 digunakan sebagai identitas objek dari Sandwich, Objek Sandwich akan muncul ketika kamera mendeteksi marker 2 pada titik yang sudah ditentukan.

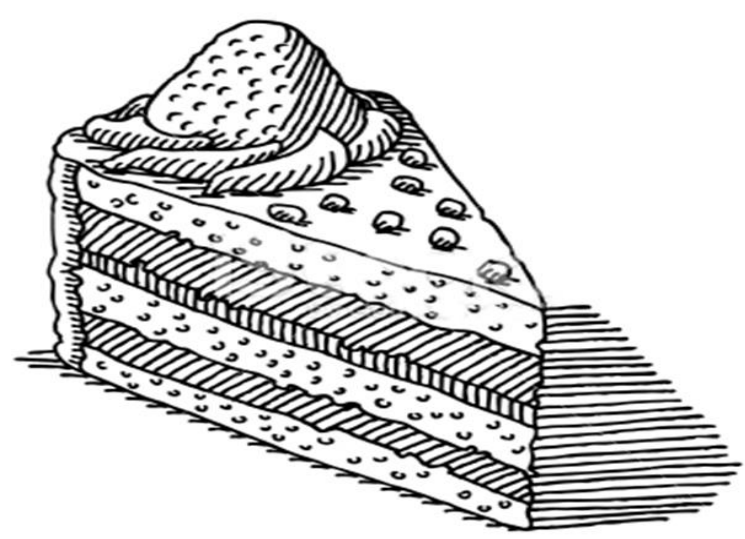

Gambar 17. Marker 3
Marker 3 digunakan sebagai identitas objek dari Cake, Objek Cake akan muncul ketika kamera mendeteksi marker 3 pada titik yang sudah ditentukan.

\section{Implementasi Antar Muka}

Pada tahap ini dilakukan penerapan hasil perancangan antarmuka ke dalam sistem yang dibangun dengan menggunakan perangkat lunak yang telah dijelaskan sebelumnya pada spesifikasi perangkat lunak.

a. Tampilan Splash Screen Loading Tampilan pertama kali saat aplikasi dibuka akan memunculkan menu loading sebelum masuk ke menu utama.

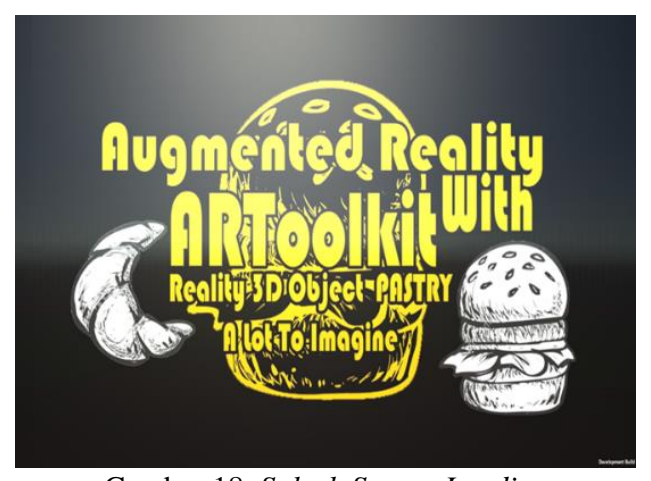

Gambar 18. Splash Screen Loading

b. Tampilan Menu Utama

Antarmuka menu utama merupakan menu yang pertama kali muncul ketika diakses oleh user. Berikut ini tampilan hasil implementasi dari menu utama

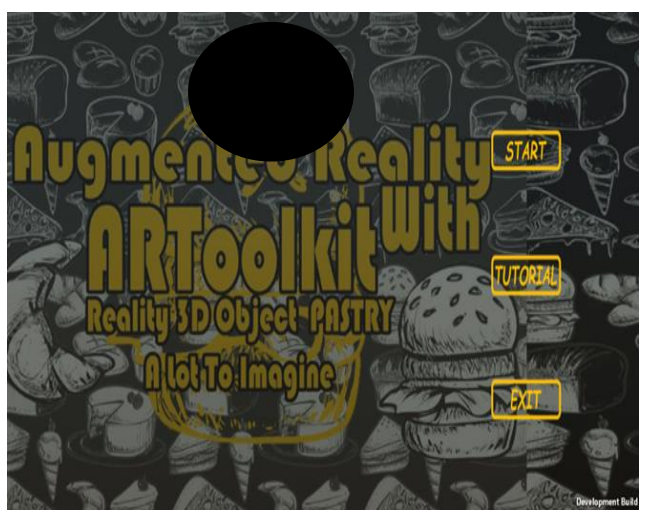

Gambar 19 Tampilan Menu Utama 
c. Tampilan Menu Panduan

Antarmuka menu panduan akan ditampilkan jika user memilih menu panduan, sistem akan merespon dengan menampilkan menu pop up yang berisi informasi tentang cara menggunakan aplikasi.

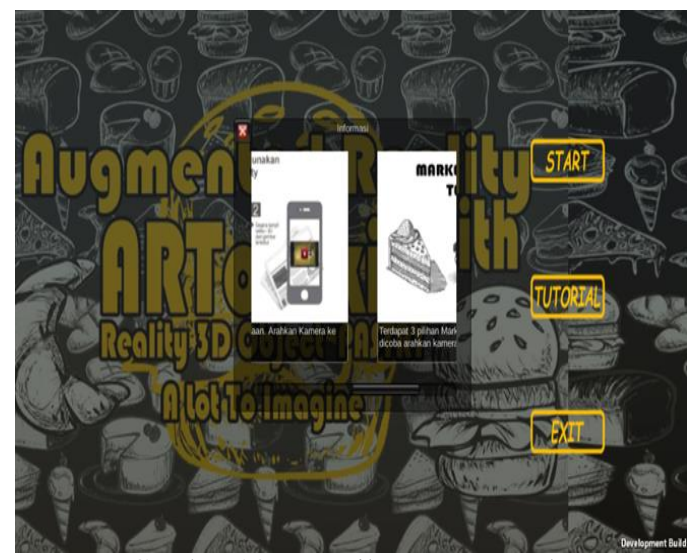

Gambar 20. Tampilan Menu Panduan

d. Tampilan Aplikasi Berjalan Antarmuka aplikasi yang sedang berjalan akan menampilkan Camera Running, yaitu antarmuka aplikasi langsung menjalankan sistem kamera pada smartphone.

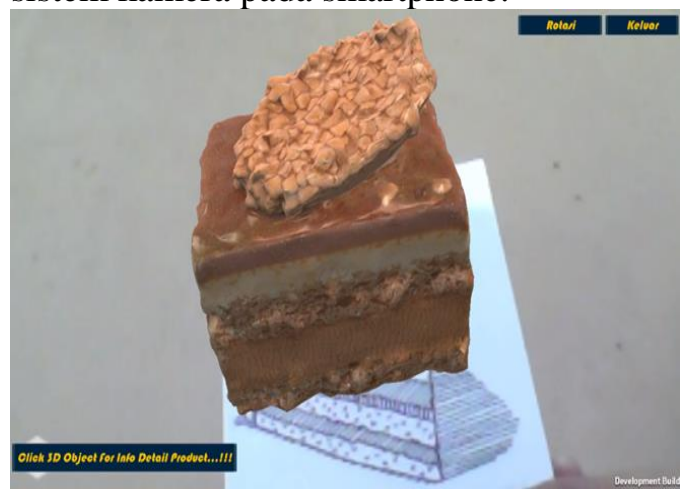

Gambar 21. Aplikasi Augmented Reality Test Marker

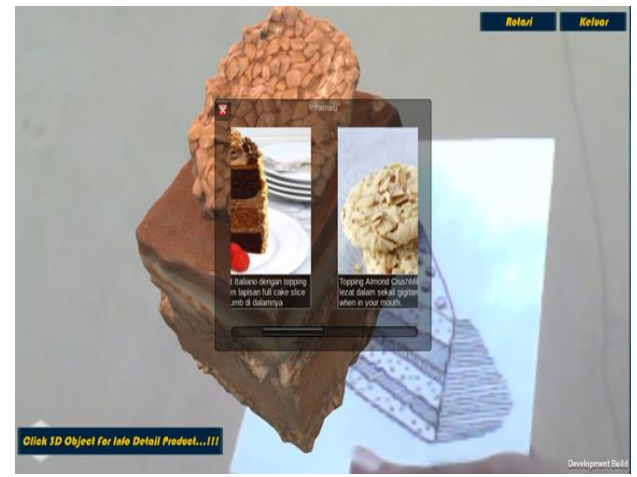

Gambar 22. Aplikasi Augmented Reality Info Produk

\section{KESIMPULAN}

Berdasarkan hasil survei yang dilakukan kepada responden terkait di Hokcafe Tangerang, Aplikasi ini dapat membantu pengunjung untuk mendapatkan informasi secara lengkap mengenai produk pastry, yaitu berupa cake, sandwich maupun croissant dalam bentuk digital.

Informasi produk Pastry yang disajikan dengan menerapkan Augmented Reality menjadi lebih efektif dan interaktif dalam memberikan informasi menggunakan brosur yang digunakan sebagai marker sehingga mampu mendorong minat pelanggan untuk membeli produk pastry.

Aplikasi ini juga membantu pengunjung dalam mengetahui informasi kelengkapan dan bagian dari suatu produk pastry

Aplikasi yang dibangun belum dapat memberikan efek transisi berskala animasi, yang mungkin diharapkan untuk mengetahui produk lebih detail ke bagian dalam produk, misal bagian lapisan dari pastry.

aplikasi Katalog AR dapat dikembangkan lebih lanjut tidak hanya berbasis Android Mobile, tetapi juga berbasis platform lainnya, seperti pada platform ios, dekstop, dan website.

Interaksi augmented reality pada aplikasi yang dibangun saat ini pemicunya berasal dari sentuhan pada layar smartphone/perangkat mobile, untuk pengembangan selanjutnya disarankan untuk ke depannya agar trigger dalam interaksi augmented reality menggunakan sentuhan tangan langsung ke objek augmented reality tanpa menyentuh layar smartphone/perangkat mobile. 


\section{REFERENSI}

[1] Abd, Rachman Arief. (2005). Pengantar Ilmu Perhotelan dan Restoran.Yogyakarta :Graha Ilmu.

[2] Adi Nugroho. (2009). Rekayasa Perangkat Lunak Menggunakan UML Dan Java. ANDI, Yogyakarta

[3] Hendi, H. (2013). The Magic Of Blender 3d Modelling. Bandung: Informatika.

[4] Haryati, S. (2012). Research \& Development (R\&D) Sebagai Salah Satu Model Penelitian Dalam Bidang Pendidikan. FKIP-UTM Vol. 37, 11-26.

[5] (https://unity3d.com/).

[6] (https://www.blender.org/about/).

[7] Bayuaji, Arief. (2015). Pengusaha UKM Butuh Aplikasi Teknologi AR. Diakses dari

http://ekonomi.inilah.com/read/detail/22464 45/pengusaha-ukm-butuhaplikasiteknologi-ar.

[8] Migran, P., \& Khisino, A.F. (1994). Taxonomy of Mixed Reality Visual Displays. Diakses dari : http://vered.rose.utoronto.ca/people/paul $\left\{_{-}\right.$ \}dir/IEICE94/ieice.html.

[9] Finley, Klint. (2010). Augmented Reality Medical App. Diakses dari : http://technoccult.net/archives/2010/01/11/a ugmented-reality-medical-app/. 